\title{
Terrain Segmentation of Greece Using the Spatial and Seasonal Variation of Reference Crop Evapotranspiration
}

\author{
Vassilis Aschonitis, ${ }^{1}$ George Miliaresis, ${ }^{2}$ Kleoniki Demertzi, ${ }^{3}$ and Dimitris Papamichail ${ }^{3}$ \\ ${ }^{1}$ Department of Life Sciences and Biotechnology, University of Ferrara, Via L. Borsari 46, 44121 Ferrara, Italy \\ ${ }^{2}$ Environmental Conservation \& Management, Faculty of Pure and Applied Sciences, Open University of Cyprus, \\ Latsia, P.O. Box 12794, 2252 Nicosia, Cyprus \\ ${ }^{3}$ Department of Hydraulics, Soil Science and Agricultural Engineering, Aristotle University of Thessaloniki, \\ University Campus, 54124 Thessaloniki, Greece \\ Correspondence should be addressed to Vassilis Aschonitis; schvls@unife.it
}

Received 13 May 2015; Accepted 8 September 2015

Academic Editor: Jorge E. Gonzalez

Copyright (C) 2016 Vassilis Aschonitis et al. This is an open access article distributed under the Creative Commons Attribution License, which permits unrestricted use, distribution, and reproduction in any medium, provided the original work is properly cited.

\begin{abstract}
The study presents a combination of techniques for integrated analysis of reference crop evapotranspiration (ET ( $_{o}$ ) in GIS environment. The analysis is performed for Greece and includes the use of (a) ASCE-standardized Penman-Monteith method for the estimation of 50-year mean monthly $\mathrm{ET}_{o}$, (b) cross-correlation and principal components analysis for the analysis of the spatiotemporal variability of $\mathrm{ET}_{o}$, (c) $K$-means clustering for terrain segmentation to regions with similar temporal variability of $\mathrm{ET}_{o}$, and $(\mathrm{d})$ general linear models for the description of $\mathrm{ET}_{o}$ based on clusters attributes. Cross-correlation revealed a negative correlation of $\mathrm{ET}_{o}$ with both elevation and latitude and a week positive correlation with longitude. The correlation between $\mathrm{ET}_{0}$ and elevation was maximized during the warm season, while the correlation with latitude was maximized during winter. The first two principal components accounted for the $97.9 \%$ of total variance of mean monthly $\mathrm{ET}_{o}$. $K$-means segmented Greece to 11 regions/clusters. The categorical factor of cluster number together with the parameters of elevation, latitude, and longitude described satisfactorily the $\mathrm{ET}_{0}$ through general linear models verifying the robustness of the cluster analysis. This research effort can contribute to hydroclimatic studies and to environmental decision support in relation to water resources management in agriculture.
\end{abstract}

\section{Introduction}

The evapotranspiration rate, which can be achieved under no water restrictions from a well-watered ideal grass surface, is called reference crop evapotranspiration $\mathrm{ET}_{o}$ and it is one of the most important hydroclimatic parameters for the implementation of various hydrological and agricultural applications [1]. Various methods have been developed for the assessment of $\mathrm{ET}_{o}[2,3]$ and the ASCE-standardized Penman-Monteith method, which is an update of the FAO56 Penman-Monteith, has been proposed by the ASCEEWRI Task Committee as the most precise method for $\mathrm{ET}_{o}$ estimations [2].

The intra-annual and spatial variability of the $\mathrm{ET}_{o}$ for regions of Greece has been investigated using different methods by many authors [4-18]. The latest and the most detailed mean monthly $\mathrm{ET}_{o}$ estimations at country scale based on FAO Penman-Monteith method [1] have been performed by Dalezios et al. [5] using 66 meteorological stations covering a period of 15 years. The authors used the kriging technique for the development of $50 \mathrm{~km}$ resolution grids. Mardikis et al. [11] tested different interpolation methods for $\mathrm{ET}_{o}$ based on 93 meteorological stations and provided improved methods which include the effect of elevation.

The last years, the use of climatic models succeeded to generate high resolution grids of various climatic parameters which enabled the development of global $\mathrm{ET}_{o}$ maps. Significant works of long-term mean $\mathrm{ET}_{o}$ estimations at global scales have been performed by many authors [1922]. $\mathrm{ET}_{o}$ maps using the FAO-56 Penman-Monteith and ASCE-standardized Penman-Monteith method, which are the most demanding methods in terms of climatic data and 
elaboration, have been developed at resolutions of 10 arc-min [20] and 0.5 degrees [21] (1 degree $=60$ arc- $\min =3600$ arc$\mathrm{sec} \approx 111 \mathrm{~km}$ at equator). The highest spatial resolution $\mathrm{ET}_{o}$ maps (30 arc-sec) have been developed [22] using the simple method of Hargreaves [23], which requires only temperature data.

Grids of mean monthly $\mathrm{ET}_{o}$ can be used in an attempt to capture the spatial and seasonal patterns and to segment the terrain to regions with distinct seasonal $\mathrm{ET}_{o}$ variability. Common approaches for such analysis are the typical multivariate methods such as correlation analysis, principal components, factorial kriging analysis, multi-Gaussian co-kriging, regression analysis, and so forth, which have successfully been used for other environmental quality parameters [24-30]. In addition, terrain segmentation techniques have been applied to multitemporal land surface temperature (LST) data in an attempt to define subregions with different seasonal LST variability, to assess its sensitivity to climatic change by revealing thermal anomalies and to support environmental analysis [31-36]. Similar regionalization and segmentation approaches have also been applied successfully in order to define subregions with different seasonal precipitation patterns [37-39].

Objectives of the study are (a) to develop high resolution grids ( $30 \mathrm{arc}-\mathrm{sec}$ ) of 50-years mean monthly $\mathrm{ET}_{o}$ for Greece using the ASCE-standardized Penman-Monteith, (b) to analyze the spatiotemporal variability of $\mathrm{ET}_{o}$, and (c) to provide a terrain segmentation scheme for Greece based on the spatiotemporal variation of $\mathrm{ET}_{o}$. The techniques of cross-correlation, principal components (PCA), cluster analysis, and general linear models (GLMs) were used. Cross-correlation and PCA are used to capture the dependence of spatiotemporal variation of mean monthly $\mathrm{ET}_{o}$ on geographical attributes (latitude and longitude), topography (elevation), and seasonality. $K$-means clustering is used to segment the Greek territory to regions/clusters in which the mean monthly $\mathrm{ET}_{o}$ observations approximate to representative mean values with similar temporal variability. GLMs are used to (a) to parameterize the effect of clusters and together with elevation, latitude, and longitude to build models which can provide estimations of mean monthly $\mathrm{ET}_{o}$ (b) to verify the robustness of the cluster analysis and (c) to assess the contribution/effect of each cluster in the mean monthly $\mathrm{ET}_{o}$ estimations. This effort will be valuable in assisting environmental decision support and agricultural planning in relation to water resources management.

\section{Data and Methods}

2.1. Study Area and Data. The study area is Greece (SouthEast Europe) which is confined between the $34^{\circ}$ and $42^{\circ}$ parallel N., with a meridional extent from $19^{\circ}$ to $28^{\circ}$ E. Greece has a typical Mediterranean climate: relatively cold and rainy winters, relatively warm and dry summers, and, generally, extended periods of sunshine. The spatial heterogeneity of climate is mainly attributed to the mountain range of Pindos located in the central part of Greece, while significant differences in the winter's severity are observed between the central-north continental territory and the islands where in the second case the winter is milder (Hellenic National Meteorological Service: http://www.hnms.gr/hnms/english/ climatology/climatology html).

The analysis was based on climatic data, which were obtained from the following databases:

(i) [40]: this database provides mean monthly values for the parameters of maximum, minimum, and mean temperature at $30 \mathrm{arc}-\mathrm{sec}$ spatial resolution $(\sim 1 \times 1 \mathrm{~km})$. The data are provided as grids of mean monthly values of the period 19502000 (http://www.worldclim.org/). The database also includes a revised version of the GTOPO30 DEM based on SRTM DEM at 30 arc-sec spatial resolution. The data were produced using observation-based datasets after elaboration with the thin-plate smoothing spline algorithm implemented in the ANUSPLIN package for interpolation, using latitude, longitude, and elevation as independent variables.

(ii) [41]: this database provides mean monthly values of parameters such as solar radiation, specific humidity, wind speed at $10 \mathrm{~m}$ above surface (which was converted to $2 \mathrm{~m}$ above surface), precipitation, and temperature for the period 1948-2006 at 0.5 degrees spatial resolution. The dataset was constructed by combining a suite of global observation-based datasets and it is available in the form of NetCDF files (Network Common Data Form) of monthly values of each year for the period 1948-2006 (http://hydrology .princeton.edu/data.pgf.php). Resampling to 30 arcsec spatial resolution was performed using the bilinear resampling scheme. The data were converted to grids of mean monthly values of the period 1950 2000 .

2.2. Reference Crop Evapotranspiration. The estimation of $\mathrm{ET}_{o}$ using the ASCE-standardized Penman-Monteith method is performed by the following equation [2]:

$$
\begin{aligned}
& \mathrm{ET}_{o} \\
& =\frac{0.408 \Delta\left(R_{n}-G\right)+\gamma u_{2}\left(e_{s}-e_{a}\right) C_{n} /\left(T_{\text {mean }}+273.16\right)}{\Delta+\gamma\left(1+C_{d} u_{2}\right)},
\end{aligned}
$$

where $\mathrm{ET}_{o}$ is the daily reference crop evapotranspiration $\left(\mathrm{mm} \mathrm{d}^{-1}\right), R_{n}$ is the daily net radiation at the crop surface (MJ m ${ }^{-2} \mathrm{~d}^{-1}$ ), $u_{2}$ is the mean daily wind speed at $2 \mathrm{~m}$ height above the soil surface $\left(\mathrm{m} \mathrm{s}^{-1}\right), T_{\text {mean }}$ is the mean daily air temperature $\left({ }^{\circ} \mathrm{C}\right), G$ is the daily soil heat flux density at the soil surface $\left(\mathrm{MJ} \mathrm{m}^{-2} \mathrm{~d}^{-1}\right), e_{s}$ is the mean daily saturation vapour pressure $(\mathrm{kPa}), e_{a}$ is the mean daily actual vapour pressure $(\mathrm{kPa}), \Delta$ is the slope of the saturation vapour pressuretemperature curve $\left(\mathrm{kPa}^{\circ} \mathrm{C}^{-1}\right), \gamma$ is the psychometric constant $\left(\mathrm{kPa}^{\circ} \mathrm{C}^{-1}\right), C_{n}$ and $C_{d}$ are constants, which vary according to the time step and the reference crop type and describe the bulk surface resistance and aerodynamic roughness. The short reference crop corresponds to clipped grass of $12 \mathrm{~cm}$ height and surface resistance of $70 \mathrm{~s} \mathrm{~m}^{-1}$ where the constants $C_{n}$ and $C_{d}$ have the values 900 and 0.34 , respectively. 
The tall reference crop corresponds to full cover alfalfa of $50 \mathrm{~cm}$ height and surface resistance of $45 \mathrm{~s} \mathrm{~m}^{-1}$, where the constants $C_{n}$ and $C_{d}$ have the values 1600 and 0.38 , respectively [2]. In this study, the $\mathrm{ET}_{o}$ is estimated using (1) for the commonly used short reference crop as follows: (a) mean monthly values of maximum, minimum, and mean temperature were obtained from the database of [40], while (b) wind speed, specific humidity, and solar radiation were obtained from the database of [41]. The specific humidity was converted to actual vapour pressure [42] before its use. The equations used for intercalculations in ASCE method are given in $[2,43,44]$. All the calculations were performed in ArcGIS 9.3 ESRI environment. Twelve rasters (one for each month) of mean monthly $\mathrm{ET}_{o}$ plus one of mean annual $\mathrm{ET}_{o}$ of the period 1950-2000 were developed for the Greek territory.

2.3. Methodology for Terrain Segmentation Based on the Annual and Seasonal Variation of a Hydroclimatic Parameter. A set of four statistical methods such as cross-correlation analysis, principal component analysis, $K$-means cluster analysis, and general linear models [45-48] are used in this study. Correlation analysis and principal component analysis (PCA) reveal the temporal and spatial pattern evident within a multitemporal dataset. PCA is a linear transformation technique that produces a set of images known as principal components PCs that are uncorrelated with one another while they are ordered in terms of the amount of variance they explain from the original image set $[49,50]$. PCs are computed from the linear combination of eigenvectors and the corresponding pixel values of the initial images [51]. PCA has traditionally been used in remote sensing as a means of data compaction since it is usually observed that the first 2 or 3 components are able to explain the majority of the variability in data values. Later components thus tend to be dominated by noise effects. By rejecting these later components, the volume of data is reduced, with no appreciable loss of information [52]. Standardized principal components analysis [53] is applied (data per month is centered with mean 0.0 and standard deviation 1.0) and so each image is not weighed according to its variance.

$K$-means cluster analysis was used to partition the multitemporal (12-dimensional) imagery of $\mathrm{ET}_{o}$ into $K$ exclusive clusters. It begins by initializing cluster centroids, then assigns each pixel to the cluster whose centroid is nearest, updates the cluster centroids, and then repeats the process until the stopping criteria are satisfied [51]. The analysis uses Euclidian distance for calculating the distances between pixels and cluster centroids. The underlying idea of cluster analysis is that the cluster centroids represent the mean expression of the derived clusters. So clustering of the multitemporal data sets is expected to define groups of pixels with a rather common centroid curve that expresses their average monthly variability [32]. Elevation, latitude, and longitude statistics per cluster are computed in order to assist interpretation. Finally the clusters were interpreted according to their centroid and their spatial arrangement [36].

General multiple linear regression analysis was performed using Statgraphics Centurion software (StatPoint
Technologies). The parameterization of segmentation effects was made using an integer cluster number $\mathrm{CN}$ ranging from 1 to $K$. The $\mathrm{CN}$ categorical factor together with the quantitative factors of latitude (Lat), longitude (Lon), and elevation $(H)$ were used as independent variables to describe the mean monthly values of $\mathrm{ET}_{0}$. The values of the aforementioned parameters were extracted from 29765 randomly selected positions homogeneously distributed in the entire Greek territory. The selection was performed using the Sampling Design Tool developed by NOAA (National Oceanic and Atmospheric Administration of USA) based on the procedure of "stratified random sampling." For each month, the mean values of the dependent variable (mean monthly $\mathrm{ET}_{o}$ ) of sampling positions belonging to each cluster were compared using ANOVA-LSD. This analysis was performed in order to verify that the sampling procedure retained the differences between clusters, which were derived by $K$-means using the whole number of pixels of each cluster. Square root transformation was used for the Lat, Lon, and $H$ values while BoxCox transformation [54] was used for the mean monthly $\mathrm{ET}_{o}$ values to avoid/reduce normality deviations of the dependent and independent variables. The selection of the parameters for the regression model was performed using their variance inflation factor (VIF) in order to avoid multi-co-linearity effects. VIF values above 10 are usually considered to indicate serious multicollinearity [45]. Thus, the following linear model was built to describe the mean monthly $\mathrm{ET}_{o}(\mathrm{~mm})$ for each month:

$$
\begin{aligned}
\operatorname{BoxCox}\left(\mathrm{ET}_{o, i}\right)= & a_{0}+\sum_{j=1}^{N}\left(a_{j} \cdot I_{\mathrm{CN}, j}\right)+a_{N+1} \cdot \sqrt{\mathrm{Lon}} \\
& +a_{N+2} \cdot \sqrt{\mathrm{Lat}}+a_{N+3} \cdot \sqrt{H},
\end{aligned}
$$

where $a_{0}$ is intercept of the regression model and $a_{j}$ is the regression coefficients of the categorical factor $I_{\mathrm{CN}}$ which is regulated by the cluster number $\mathrm{CN}, a_{N+1, N+2, N+3}$ : the regression coefficients of the quantitative factors Lon, Lat (decimal degrees), and $H(\mathrm{~m})$, respectively, and $i$ is the month (starting with $i=1$ for January and ending with $i=12$ for December). The value of $N$ is equal to the number of clusters minus $1(N=K-1)$ whereas the categorical factor $I_{\mathrm{CN}}$ is regulated by the cluster number $\mathrm{CN}$ as follows:

$$
I_{\mathrm{CN}, j}= \begin{cases}1, & \text { if } \mathrm{CN}=j, \\ -1, & \text { if } \mathrm{CN}=N+1=K, \\ 0, & \text { if } \mathrm{CN} \neq j, K .\end{cases}
$$

The general form of BoxCox transformation for the dependent variable $\mathrm{ET}_{o}$ for each month $i$ is given according to the following formula [54]:

$$
\operatorname{Box} \operatorname{Cox}\left(\mathrm{ET}_{o, i}\right)=1+K_{1}\left[\left(\mathrm{ET}_{o, i}+\lambda_{2}\right)^{\lambda_{1}}-1\right]
$$

$$
\text { for } \lambda_{1} \neq 0 \text {, }
$$




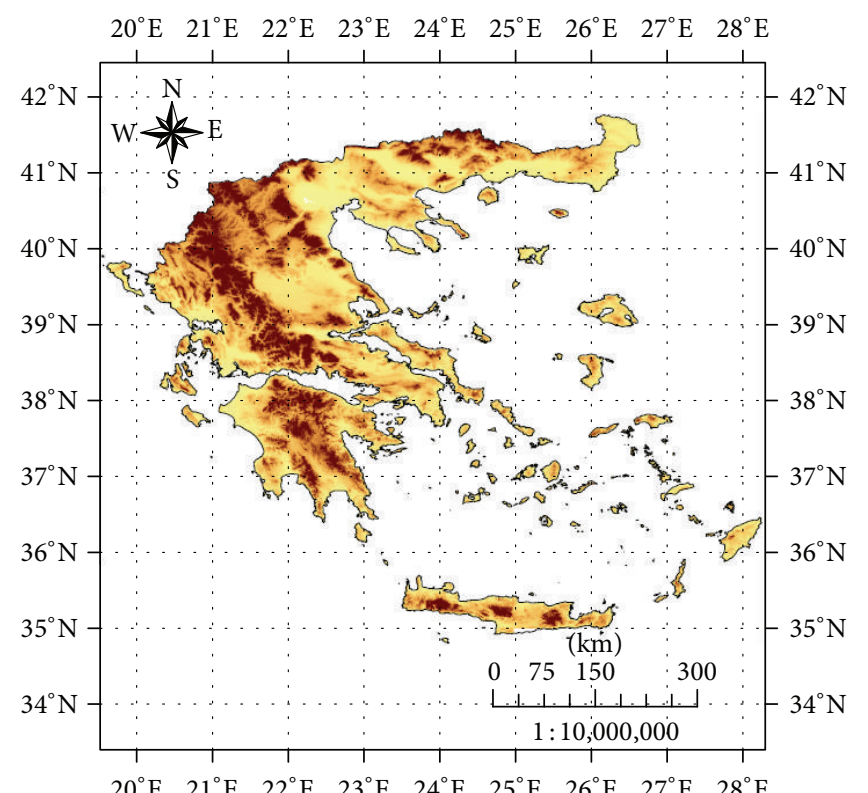

$\begin{array}{lllllllll}20^{\circ} \mathrm{E} & 21^{\circ} \mathrm{E} & 22^{\circ} \mathrm{E} & 23^{\circ} \mathrm{E} & 24^{\circ} \mathrm{E} & 25^{\circ} \mathrm{E} & 26^{\circ} \mathrm{E} & 27^{\circ} \mathrm{E} & 28^{\circ} \mathrm{E}\end{array}$
Low: 1

Elevation ( $m$ a.s.l.)

(a)

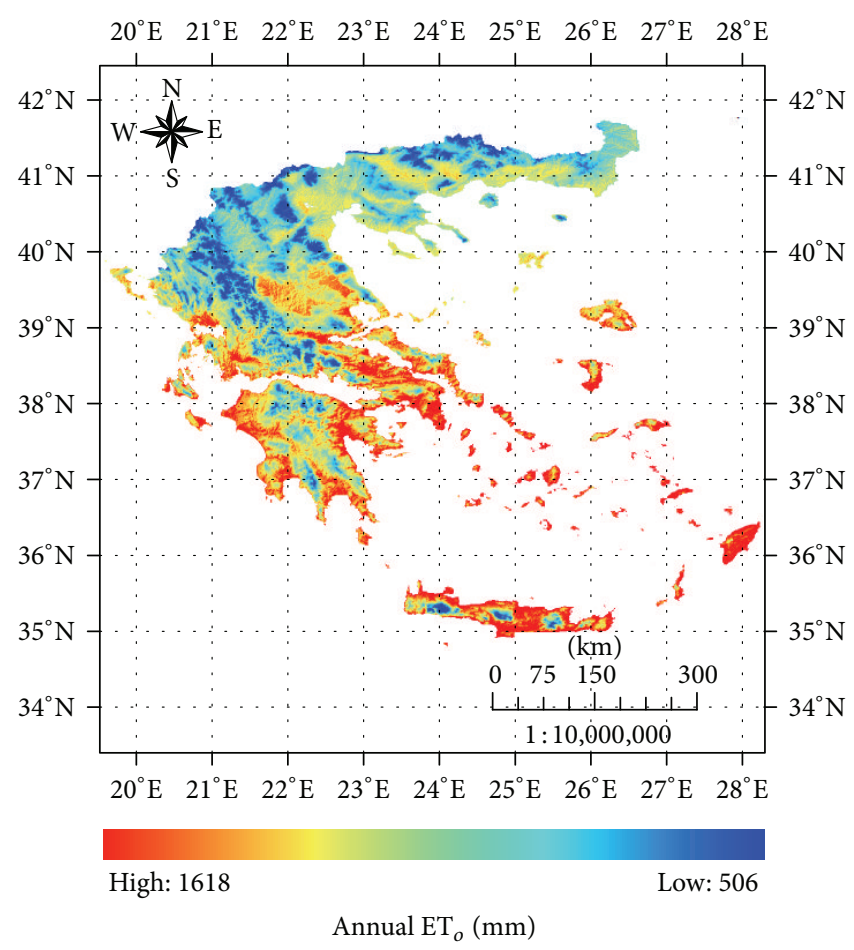

(b)

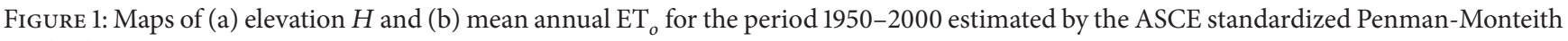
method.

$$
\begin{aligned}
& K_{1}=\frac{1}{\lambda_{1} K_{2}^{\lambda_{1}-1}}, \\
& K_{2}=\left[\prod_{k=1}^{n}\left(\mathrm{ET}_{o, i, k}+\lambda_{2}\right)\right]^{1 / n},
\end{aligned}
$$

where $\lambda_{1,2}$ is the power and shift parameters of BoxCox transformation, respectively, and $n$ is the number of $\mathrm{ET}_{o}$ observations (samples) for a month $i$. Note that $K_{2}$ is the geometric mean of $\mathrm{ET}_{o}+\lambda_{2}$. In order to improve the efficiency of the model, the power parameter $\lambda_{1}$ was optimized while the shift parameter $\lambda_{2}$ was set to 0 based on the default optimization procedure incorporated in the statistical software. The optimal transformation is the one that minimizes the mean squared error of the transformed dependent variable [54].

Outliers were not removed during the regression analysis because of the large number of data (there is no automatic procedure to remove outliers). Autocorrelation of the residuals was tested using the Durbin-Watson test $[55,56]$, which provides values between 0 and 4 where the optimum value for no autocorrelation is equal to 2. ANOVA was used to estimate the statistical significance of the regression model while square correlation coefficient $R^{2}$ adjusted for degrees of freedom was used to evaluate the explanatory power of the model. Type III sums of squares analysis was used to estimate the statistical significance of the independent variables $\mathrm{CN}$, Lat, Lon, and $H$.

\section{Results and Discussion}

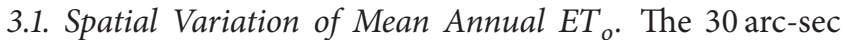
resolution $(\sim 1 \times 1 \mathrm{~km})$ maps of elevation $H$ and mean reference crop evapotranspiration $\mathrm{ET}_{o}$ for the period 19502000 estimated by the ASCE standardized Penman-Monteith method are given in Figures 1(a) and 1(b), respectively, while the frequency distributions of pixel values are given, respectively, in Figures 2(a) and 2(b).

The $\mathrm{ET}_{o}$ map (Figure 1(b)) indicates that the lowland areas (below $250 \mathrm{~m}$ ) with a distance less than $20-25 \mathrm{~km}$ from the shoreline and with latitude less than 39 degrees present annual values of $\mathrm{ET}_{o}>1200 \mathrm{~mm}$. Regions with extremely high mean annual $\mathrm{ET}_{o}$ values $>1400 \mathrm{~mm}$ occupy approximately $13.5 \%$ of the Greek territory and they are distributed mainly to lowlands along the coastlines of (a) Crete and Dodecanese islands (southern and eastern Aegean Sea), (b) eastern Attika, and (c) eastern Peloponnesus. These findings are in accordance to the study of [5] who used a $50 \mathrm{~km}$ resolution grid and the studies of $[57,58]$ who analyzed data from meteorological stations.

3.2. Spatial and Seasonal Variation of Mean Monthly ET . The correlation matrix of the mean monthly values of reference evapotranspiration $\mathrm{ET}_{o}$ versus $H$, Lat, and Lon is quantified in Table 1 . According to Table 1, the mean monthly $\mathrm{ET}_{o}$ presents negative correlations with $H$ and Lat while a rather week positive correlation between $\mathrm{ET}_{o}$ and Lon exists. The absolute values of $\mathrm{ET}_{o}-H$ correlations are maximized during the warm season while the $\mathrm{ET}_{o}$-Lat correlations are 


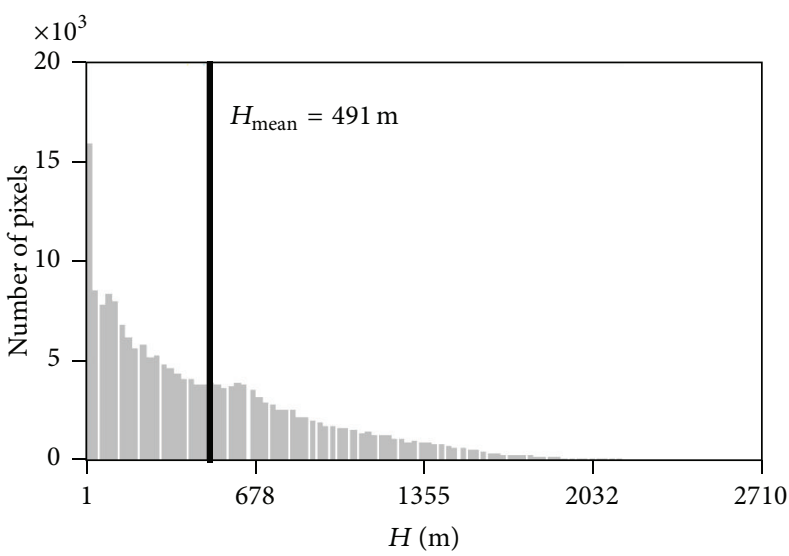

(a)

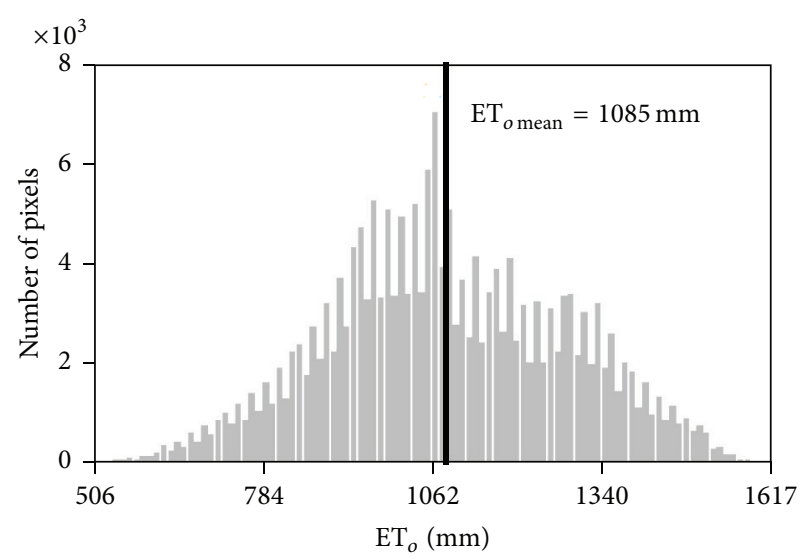

(b)

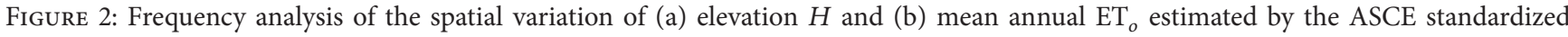
Penman-Monteith method for the period 1950-2000.

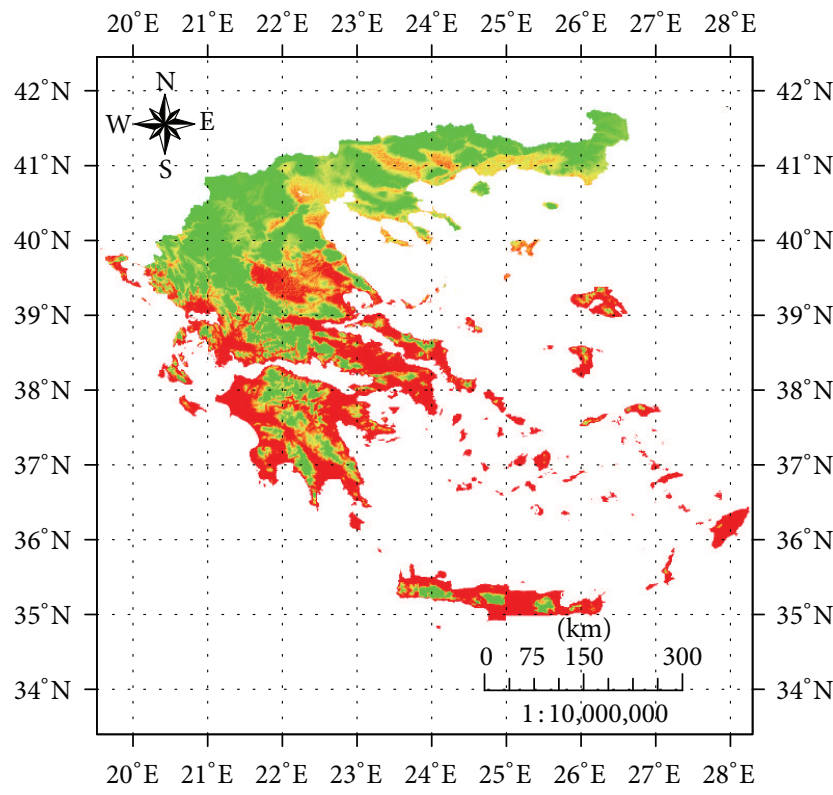

High: 9.65727
Low: -9.49924

PC1-ETo

(a)

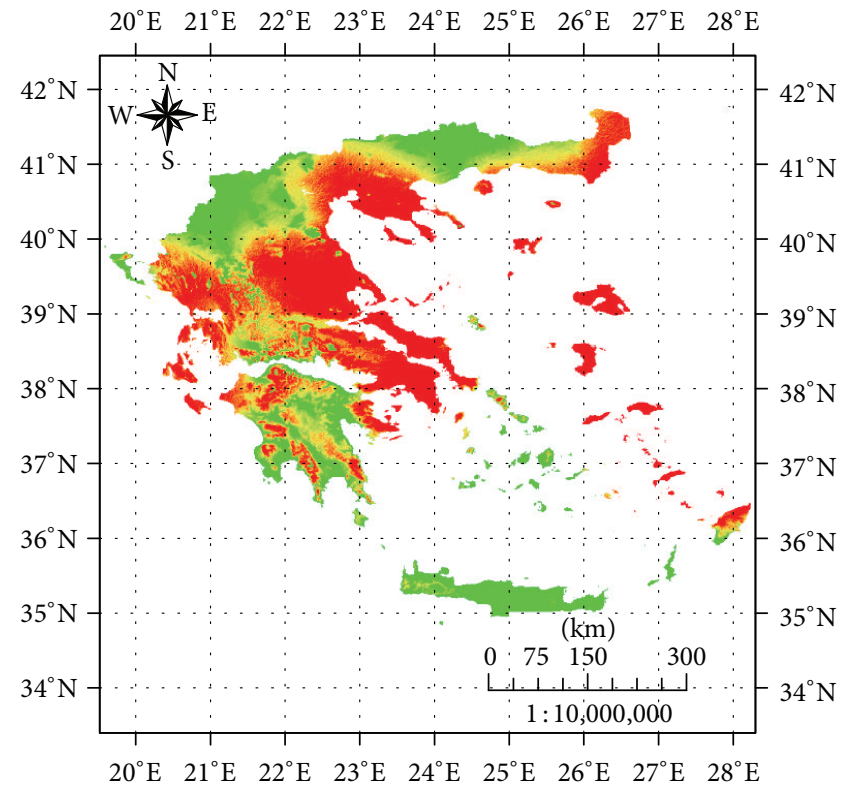

High: 2.97096 Low: -3.59423

PC2-ET

(b)

FIGURE 3: The first two principal components PC-1 and PC-2 that account for the $97.9 \%$ of the $\mathrm{ET}_{o}$ variance.

maximized during the winter. The absolute values of $\mathrm{ET}_{o}$-Lon correlations are generally low and they are maximized during the period of August-January.

PCA was implemented in order to interpret the monthly intercorrelations observed in Table 1 and the corresponding eigenvalues and eigenvectors are presented in Table 2. According to the eigenvalues, the first two principal components (PC-1 and PC-2) account for the $97.9 \%$ of the total variance observed in the 12 monthly $\mathrm{ET}_{o}$ images.

The PC-1 map (Figure 3(a)) is composed of linear combinations of monthly $\mathrm{ET}_{o}$ images which are not influenced by seasonality since the weights of eigenvectors slightly vary between 0.28 and 0.30 (Table 2). Taking into account the correlation coefficients of monthly $\mathrm{ET}_{o}$ versus $H$ and Lat from Table 1, it is easy to detect that PC-1 amplifies the effects of elevation and latitude. The effects of elevation and latitude indirectly express the effects of temperature, which is higher in the lowlands but also higher in lower latitudes. The PC1 is spatially maximised in the lowlands of the southern continental Greece and in the islands.

For PC-2 map (Figure 3(b)), the linear combinations of monthly $\mathrm{ET}_{o}$ images amplify the difference between 
TABLE 1: Cross-correlation matrix of the mean monthly ET (January to December) as well as the latitude, longitude, and elevation images. Correlations are performed between pairs of variables taking values from pixels of the same geographical position.

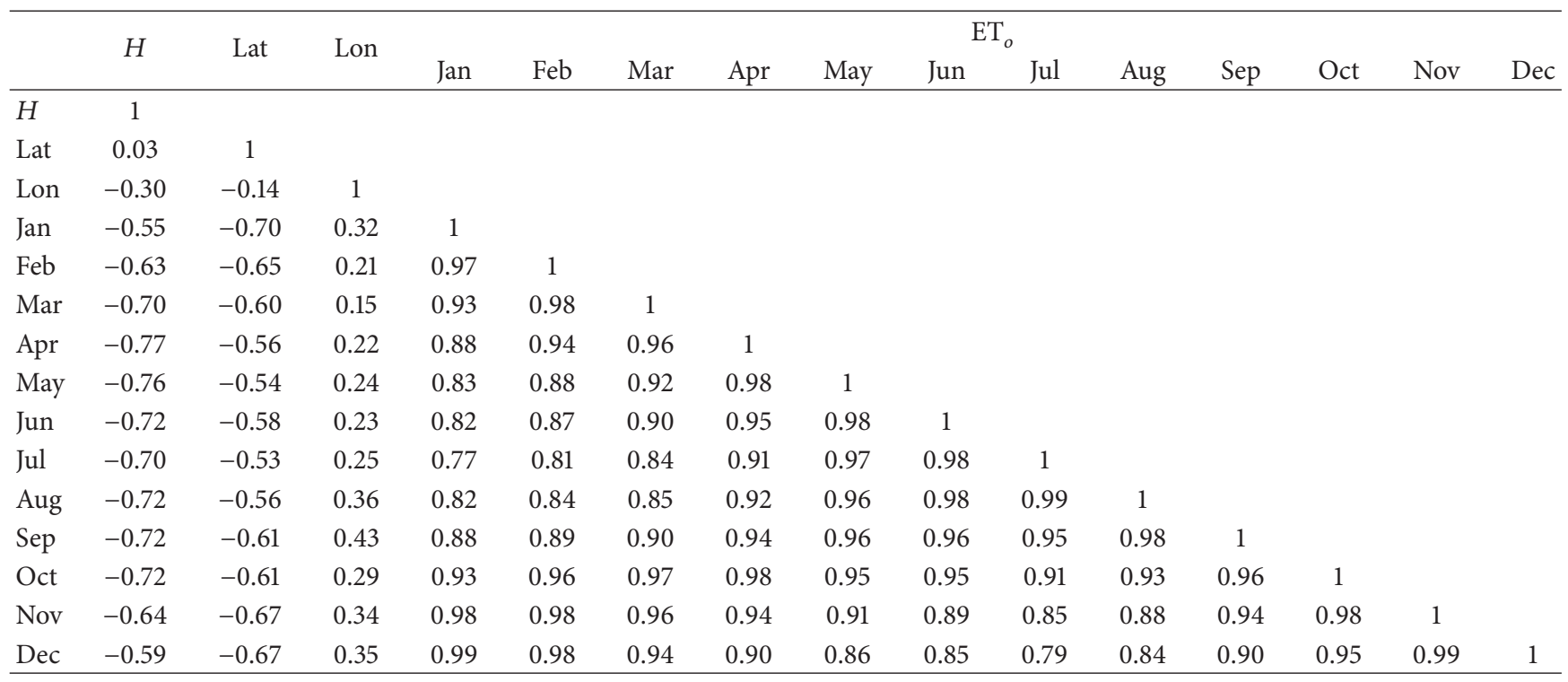

TABLE 2: Eigenvalues and eigenvectors for the PCs of the mean monthly $\mathrm{ET}_{o}$.

\begin{tabular}{|c|c|c|c|c|c|c|c|c|c|c|c|c|}
\hline \multirow[b]{2}{*}{ Eigenvectors } & \multicolumn{12}{|c|}{ Principal components (PCs) } \\
\hline & 1 & 2 & 3 & 4 & 5 & 6 & 7 & 8 & 9 & 10 & 11 & 12 \\
\hline Jan & 0.28 & -0.41 & 0.33 & -0.19 & -0.40 & -0.03 & 0.00 & 0.04 & -0.44 & 0.33 & -0.34 & -0.17 \\
\hline Feb & 0.29 & -0.32 & -0.16 & -0.36 & 0.06 & 0.06 & 0.16 & -0.52 & 0.10 & 0.21 & 0.50 & 0.20 \\
\hline Mar & 0.29 & -0.20 & -0.49 & -0.19 & 0.11 & 0.61 & -0.02 & 0.22 & 0.03 & -0.28 & -0.28 & -0.14 \\
\hline Apr & 0.29 & 0.05 & -0.46 & 0.39 & -0.14 & -0.39 & 0.09 & -0.43 & -0.09 & -0.12 & -0.39 & 0.11 \\
\hline May & 0.29 & 0.25 & -0.25 & 0.19 & -0.58 & 0.04 & -0.26 & 0.26 & -0.06 & 0.06 & 0.51 & -0.16 \\
\hline Jun & 0.29 & 0.31 & -0.08 & -0.30 & 0.07 & -0.31 & 0.66 & 0.39 & 0.11 & 0.13 & -0.03 & -0.09 \\
\hline Jul & 0.28 & 0.44 & 0.11 & -0.46 & 0.00 & -0.05 & -0.47 & -0.02 & 0.01 & -0.04 & -0.21 & 0.48 \\
\hline Aug & 0.28 & 0.35 & 0.34 & -0.04 & 0.11 & 0.12 & -0.01 & -0.44 & 0.02 & -0.25 & 0.01 & -0.63 \\
\hline Sep & 0.29 & 0.17 & 0.34 & 0.46 & 0.02 & 0.49 & 0.33 & -0.01 & -0.06 & 0.10 & 0.00 & 0.44 \\
\hline Oct & 0.30 & -0.04 & -0.08 & 0.21 & 0.67 & -0.16 & -0.28 & 0.18 & -0.39 & 0.28 & 0.16 & -0.10 \\
\hline Nov & 0.29 & -0.24 & 0.15 & 0.20 & 0.02 & -0.10 & -0.23 & 0.11 & 0.78 & 0.27 & -0.16 & -0.10 \\
\hline Dec & 0.28 & -0.36 & 0.28 & 0.04 & 0.01 & -0.29 & 0.01 & 0.21 & -0.03 & -0.71 & 0.21 & 0.16 \\
\hline Eigenvalue & 11.13 & 0.62 & 0.15 & 0.04 & 0.02 & 0.01 & 0.01 & 0.01 & 0.01 & 0.00 & 0.00 & 0.00 \\
\hline Variance $\%$ & 92.71 & 5.17 & 1.25 & 0.32 & 0.18 & 0.12 & 0.08 & 0.06 & 0.04 & 0.04 & 0.02 & 0.02 \\
\hline
\end{tabular}

the periods of October-March and April-September which present negative and positive weights of eigenvectors, respectively (Table 2). The difference between these two periods is spatially maximised in central Greece, in central Macedonia (Thessaloniki plain and Chalkidiki regions), in eastern Thrace, in the islands of north-eastern Aegean sea and south Ionian sea. These patterns are in accordance with the spatiotemporal patterns given by $[5,8,59]$.

\subsection{Terrain Segmentation Based on the Spatial and Seasonal} Variation of $E T_{o}$. For the implementation of the $K$-means method, the following criteria were used: (a) small clusters with area extent (occurrence) less than $0.001 \%$ were eliminated by merging them with larger clusters that are closest to their centroids and the stopping criterion was defined as the percentage of the migrating pixels during a specific iteration (if it was less than $0.001 \%$ of the entire image pixels the clustering was terminated), (b) the maximum number of clusters $K$ was defined by a trial and error procedure, and (c) the maximum number of iterations was set equal to 300 . At the end of the analysis, the mean monthly values of $\mathrm{ET}_{o}$ are given for each cluster (described as multipart polygons).

Cluster analysis revealed 11 clusters $(K=11)$ in which the mean monthly $\mathrm{ET}_{o}$ observations approximate to representative mean values with similar temporal variability. The characteristics of their centroids (latitude, longitude), their percent area extent, mean elevation, and the variation of monthly $\mathrm{ET}_{o}$ are given in Table 3 . The spatial distribution of the 11 clusters is given in Figure 4. 
TABLE 3: Cluster centroids, percent area (\%), mean $H$, mean monthly, and annual $\mathrm{ET}_{o}$.

\begin{tabular}{|c|c|c|c|c|c|c|c|c|c|c|c|c|c|c|c|c|c|}
\hline \multirow{2}{*}{$\mathrm{CN}$} & \multicolumn{2}{|c|}{ Centroid } & \multirow{2}{*}{ Area \% } & \multirow{2}{*}{$H(\mathrm{~m})$} & \multicolumn{13}{|c|}{$\mathrm{ET}_{o}(\mathrm{~mm})$} \\
\hline & Lat & Lon & & & Jan & Feb & Mar & Apr & May & Jun & Jul & Aug & Sep & Oct & Nov & Dec & Annual \\
\hline 1 & 39.98 & 22.91 & 32.12 & 488 & 18 & 28 & 52 & 81 & 118 & 153 & 172 & 156 & 104 & 64 & 31 & 21 & 997 \\
\hline 2 & 40.00 & 22.51 & 13.58 & 987 & 12 & 20 & 41 & 67 & 103 & 136 & 154 & 139 & 90 & 52 & 22 & 14 & 850 \\
\hline 3 & 40.11 & 22.24 & 3.68 & 1427 & 9 & 15 & 32 & 53 & 88 & 119 & 136 & 122 & 77 & 41 & 16 & 9 & 718 \\
\hline 4 & 40.05 & 22.57 & 0.85 & 1791 & 9 & 14 & 28 & 45 & 75 & 103 & 119 & 107 & 66 & 33 & 13 & 8 & 620 \\
\hline 5 & 38.90 & 22.40 & 20.38 & 341 & 26 & 36 & 61 & 93 & 130 & 168 & 189 & 171 & 116 & 75 & 40 & 30 & 1134 \\
\hline 6 & 37.88 & 22.67 & 13.54 & 234 & 38 & 46 & 71 & 103 & 141 & 179 & 202 & 184 & 128 & 86 & 51 & 41 & 1269 \\
\hline 7 & 37.86 & 23.53 & 5.99 & 131 & 42 & 49 & 74 & 109 & 149 & 188 & 215 & 198 & 138 & 93 & 57 & 45 & 1356 \\
\hline 8 & 38.68 & 24.70 & 2.83 & 413 & 25 & 31 & 54 & 90 & 134 & 175 & 203 & 186 & 126 & 74 & 38 & 28 & 1164 \\
\hline 9 & 37.25 & 26.52 & 2.55 & 133 & 47 & 50 & 74 & 107 & 153 & 199 & 232 & 218 & 155 & 99 & 62 & 51 & 1447 \\
\hline 10 & 35.90 & 24.70 & 3.33 & 218 & 57 & 60 & 83 & 113 & 145 & 185 & 202 & 191 & 140 & 101 & 68 & 61 & 1404 \\
\hline 11 & 35.56 & 25.29 & 1.15 & 94 & 67 & 68 & 91 & 120 & 150 & 192 & 208 & 200 & 148 & 110 & 78 & 72 & 1504 \\
\hline & & Total & & & 25 & 34 & 57 & 87 & 125 & 161 & 182 & 165 & 112 & 71 & 38 & 28 & 1085 \\
\hline
\end{tabular}

TABLE 4: Number of sampling positions within each cluster and ANOVA-LSD comparisons of the mean values of the dependent variable between the 11 clusters for each month.

\begin{tabular}{|c|c|c|c|c|c|c|c|c|c|c|c|c|c|}
\hline $\mathrm{CN}$ & Sampling positions & Jan & Feb & Mar & Apr & May & Jun & Jul & Aug & Sep & Oct & Nov & Dec \\
\hline 1 & 9628 & $c^{\dagger}$ & $\mathrm{d}$ & $\mathrm{d}$ & $\mathrm{d}$ & $\mathrm{d}$ & $\mathrm{d}$ & $\mathrm{d}$ & $\mathrm{d}$ & $\mathrm{d}$ & $\mathrm{d}$ & $\mathrm{d}$ & $\mathrm{d}$ \\
\hline 2 & 4071 & $\mathrm{~b}$ & c & c & c & c & c & c & c & c & c & c & c \\
\hline 3 & 1103 & a & $\mathrm{b}$ & $\mathrm{b}$ & $\mathrm{b}$ & $\mathrm{b}$ & $\mathrm{b}$ & $\mathrm{b}$ & $\mathrm{b}$ & $\mathrm{b}$ & $\mathrm{b}$ & $\mathrm{b}$ & $\mathrm{b}$ \\
\hline 4 & 256 & $\mathrm{a}$ & $\mathrm{a}$ & $\mathrm{a}$ & $\mathrm{a}$ & $\mathrm{a}$ & $\mathrm{a}$ & $\mathrm{a}$ & a & $\mathrm{a}$ & $\mathrm{a}$ & $\mathrm{a}$ & $\mathrm{a}$ \\
\hline 5 & 6096 & e & $\mathrm{f}$ & $\mathrm{f}$ & $\mathrm{f}$ & $\mathrm{f}$ & $\mathrm{f}$ & $\mathrm{f}$ & $\mathrm{f}$ & $\mathrm{f}$ & $\mathrm{f}$ & $\mathrm{f}$ & $\mathrm{f}$ \\
\hline 6 & 4008 & $\mathrm{f}$ & $\mathrm{g}$ & $\mathrm{g}$ & $\mathrm{g}$ & $\mathrm{g}$ & $\mathrm{g}$ & g & g & $\mathrm{g}$ & g & g & g \\
\hline 7 & 1737 & g & $\mathrm{h}$ & $\mathrm{h}$ & $\mathrm{h}$ & $\mathrm{h}$ & $\mathrm{h}$ & $\mathrm{h}$ & $\mathrm{h}$ & $\mathrm{h}$ & $\mathrm{h}$ & $\mathrm{h}$ & $\mathrm{h}$ \\
\hline 8 & 847 & $\mathrm{~d}$ & $\mathrm{e}$ & e & $\mathrm{e}$ & $\mathrm{e}$ & $\mathrm{e}$ & e & e & e & $\mathrm{e}$ & e & e \\
\hline 9 & 741 & $\mathrm{~h}$ & $\mathrm{i}$ & $\mathrm{i}$ & $\mathrm{i}$ & $\mathrm{i}$ & $\mathrm{i}$ & $\mathrm{i}$ & $\mathrm{h}$ & $\mathrm{i}$ & $\mathrm{i}$ & $\mathrm{i}$ & $\mathrm{i}$ \\
\hline 10 & 961 & $\mathrm{i}$ & j & j & j & j & $\mathrm{i}$ & j & $\mathrm{i}$ & j & $\mathrm{i}$ & j & j \\
\hline 11 & 317 & $j$ & $\mathrm{k}$ & $\mathrm{k}$ & $\mathrm{k}$ & $\mathrm{k}$ & $\mathrm{j}$ & $\mathrm{k}$ & $j$ & $\mathrm{k}$ & $\mathrm{j}$ & $\mathrm{k}$ & $\mathrm{k}$ \\
\hline
\end{tabular}

${ }^{\dagger}$ Different letters indicate statistically significant differences between clusters of each month at 95\% confidence level (ANOVA-LSD).

In general, $\mathrm{ET}_{o}$ is maximized during summer and minimized during winter where the $76.7 \%$ of annual $\mathrm{ET}_{o}$ in Greece is observed during April to September (warm-dry period), while the $23.3 \%$ is observed during October to March (coldwet period) (Table 3). Clusters of significant interest are the following:

(i) Clusters 9, 10, and 11 present mean annual values of $\mathrm{ET}_{o}>1400 \mathrm{~mm}$, cluster 9 presents the highest mean monthly $\mathrm{ET}_{o}$ among all clusters during the period of May-September, and cluster 11 presents the highest mean monthly $\mathrm{ET}_{o}$ among all clusters during the period of October-April.

(ii) Clusters 3 and 4 present the lower mean annual values of $\mathrm{ET}_{o}$ and correspond to the higher elevation areas of Greece.

(iii) Clusters 1 and 5 cover the major part of the agricultural land in Greece.

3.4. Regression Models of Mean Monthly $E T_{o}$. The eleven clusters $(K=11)$ obtained by the $K$-means analysis were used to calibrate (2) for each month using the observations of monthly $\mathrm{ET}_{o}$, Lon, Lat, $H$, and $\mathrm{CN}$ values of the 29765 selected sampling positions. The sampling positions were distributed to each cluster based on the \% cluster's area extent (Table 3). Their number within each cluster is given in Table 4 . The comparison of the mean monthly values of the dependent variable (the BoxCox transformed mean monthly $\mathrm{ET}_{o}$ ) of sampling positions belonging to each cluster based on ANOVA-LSD is also given in Table 4. This analysis verified that the sampling procedure retained the differences between clusters which were derived by $K$-means taking into account the fact that only 4 out of 660 combinations of pairs comparisons were found nonstatistically different (e.g., pairs of clusters 3 and 4 for January, clusters 9 and 10 in June, clusters 7 and 9 in August, and clusters 9 and 10 in October) (Table 4).

The variance inflation factors VIFs of the selected independent variables of (2) ranged between 1.26 and 3.3 (the maximum VIF value corresponds to the transformed value of elevation). The regression coefficients and the statistical tests of general multiple regression analysis are given in Table 5 (twelve models, one for each month) whereas the respective graphs of observed versus predicted values of the BoxCox 

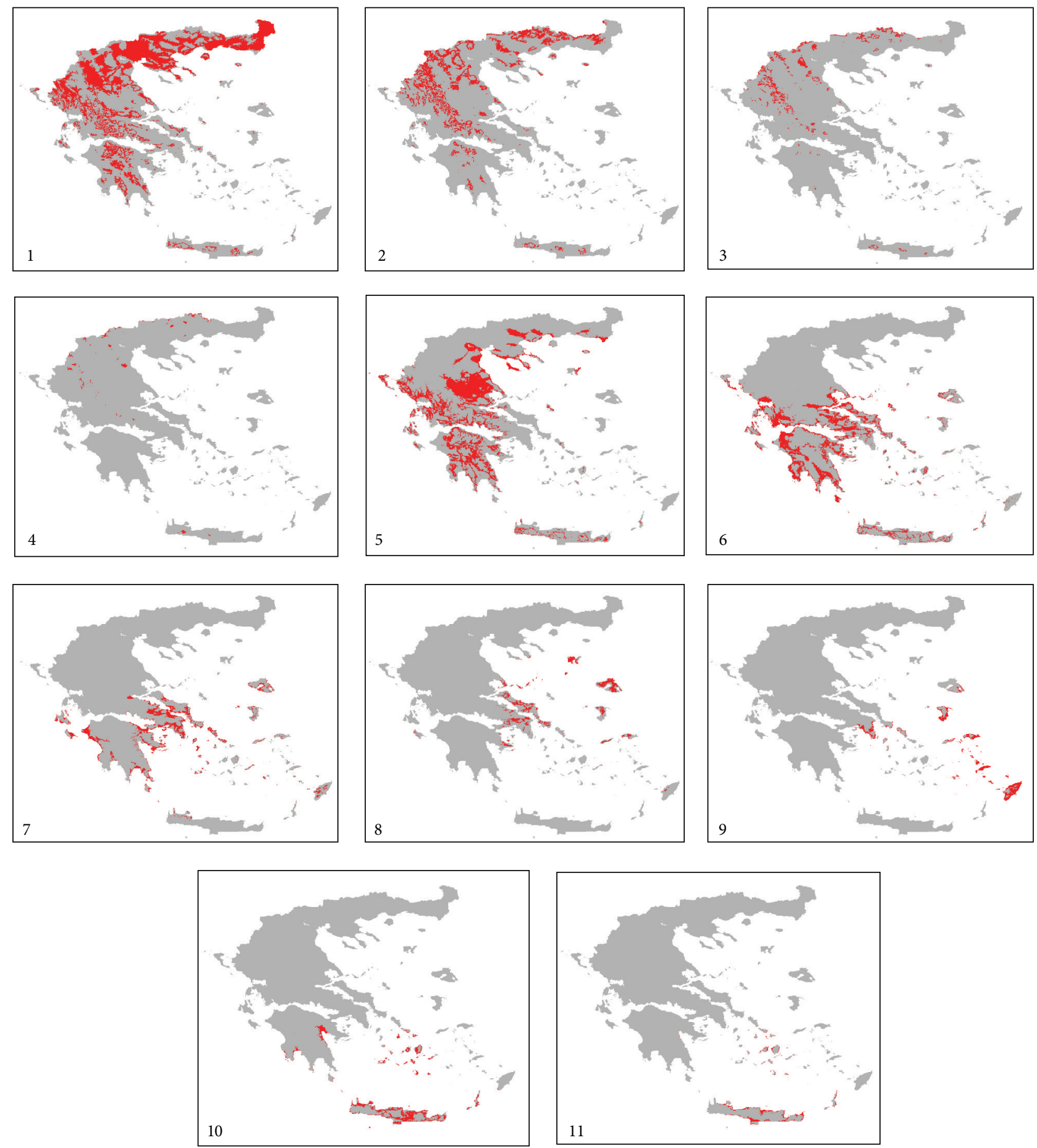

FIgURE 4: The spatial distribution of the 11 clusters of $\mathrm{ET}_{o}$ (on the bottom left corner of cluster figures are also given the $\mathrm{CN}$ values).

transformed mean monthly $\mathrm{ET}_{o}$ are given in Figure 5. For all models, type III sums of squares analysis showed that the independent variables $\mathrm{CN}$, Lat, Lon, and $H$ were statistically significant at 95\% confidence level with $p<0.001$, while the Durbin-Watson test indicated no serial autocorrelation of the residuals at $95 \%$ confidence level. Square correlation coefficients $R^{2}$ ranged between 0.88 and 0.96 indicating satisfactory accuracy of the twelve models.
The analysis of the general linear models verified the robustness of the cluster analysis in two ways (a) by the statistically significant difference between the clusters, which was derived by the ANOVA-LSD (Table 4), and (b) by the high statistical significance of the CN parameter as independent variable in the models and their high square correlation coefficients. The contribution/effect of each cluster in the spatiotemporal variation of $\mathrm{ET}_{o}$ in the Greek territory, as it 

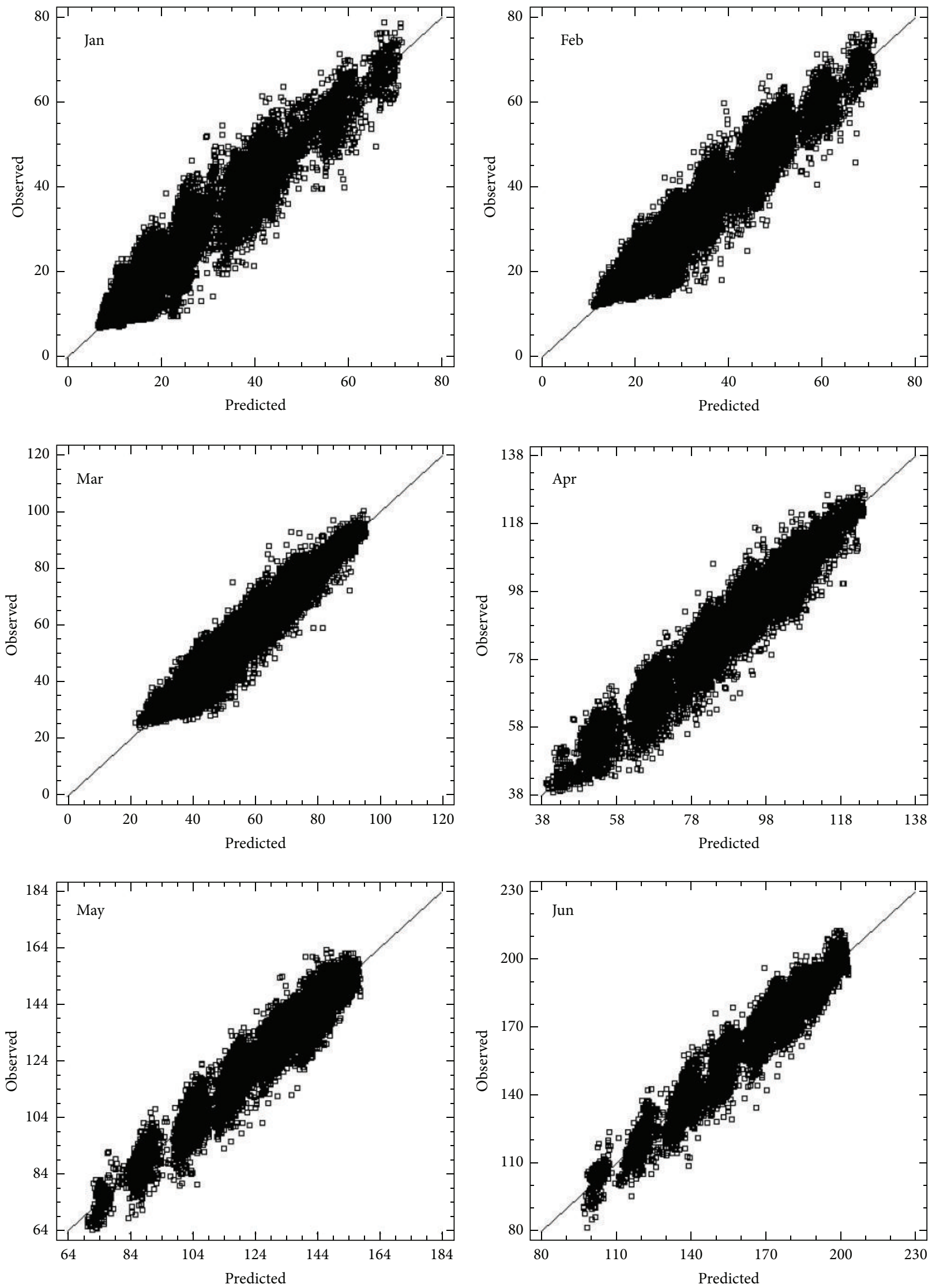

FIgure 5: Continued. 

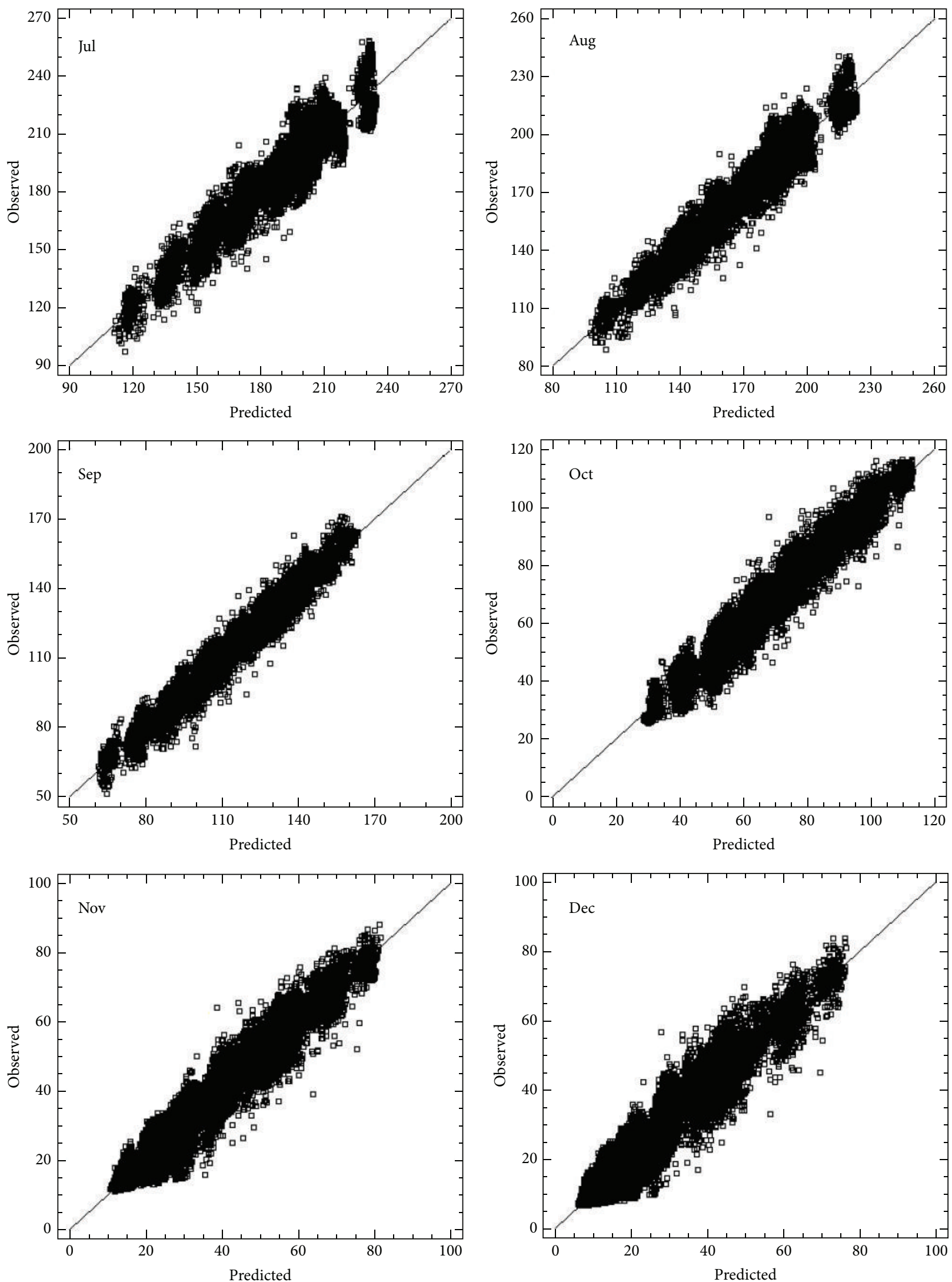

Figure 5: Observed versus predicted values of the BoxCox transformed mean monthly $\mathrm{ET}_{o}$ using the models of Table 5. 
TABLE 5: Regression coefficients and statistical tests of the general linear model described by (2) for each month.

\begin{tabular}{|c|c|c|c|c|c|c|}
\hline Month & Jan & Feb & Mar & Apr & May & Jun \\
\hline Regression coefficient & Mean \pm S.E. & Mean \pm S.E. & Mean \pm S.E. & Mean \pm S.E. & Mean \pm S.E. & Mean \pm S.E. \\
\hline$a_{0}($ intercept $)$ & $185.01 \pm 2.24$ & $193.20 \pm 2.10$ & $256.76 \pm 2.37$ & $238.60 \pm 2.25$ & $248.98 \pm 2.32$ & $315.45 \pm 2.80$ \\
\hline$a_{1}\left(I_{\mathrm{CN}, 1}\right)$ & $-7.82 \pm 0.07$ & $-7.34 \pm 0.07$ & $-7.24 \pm 0.08$ & $-7.02 \pm 0.07$ & $-6.87 \pm 0.07$ & $-9.63 \pm 0.09$ \\
\hline$a_{2}\left(I_{\mathrm{CN}, 2}\right)$ & $-11.67 \pm 0.11$ & $-12.27 \pm 0.10$ & $-13.52 \pm 0.11$ & $-15.10 \pm 0.11$ & $-16.37 \pm 0.11$ & $-20.87 \pm 0.13$ \\
\hline$a_{3}\left(I_{\mathrm{CN}, 3}\right)$ & $-13.85 \pm 0.16$ & $-16.10 \pm 0.15$ & $-19.25 \pm 0.17$ & $-23.78 \pm 0.16$ & $-27.12 \pm 0.17$ & $-32.94 \pm 0.20$ \\
\hline$a_{4}\left(I_{\mathrm{CN}, 4}\right)$ & $-14.18 \pm 0.27$ & $-16.68 \pm 0.25$ & $-20.39 \pm 0.28$ & $-27.84 \pm 0.27$ & $-35.58 \pm 0.28$ & $-43.84 \pm 0.34$ \\
\hline$a_{5}\left(I_{\mathrm{CN}, 5}\right)$ & $-2.80 \pm 0.07$ & $-1.99 \pm 0.07$ & $-1.78 \pm 0.07$ & $0.93 \pm 0.07$ & $1.41 \pm 0.07$ & $1.43 \pm 0.09$ \\
\hline$a_{6}\left(I_{\mathrm{CN}, 6}\right)$ & $4.82 \pm 0.08$ & $5.02 \pm 0.08$ & $5.74 \pm 0.09$ & $9.02 \pm 0.08$ & $10.44 \pm 0.09$ & $9.99 \pm 0.11$ \\
\hline$a_{7}\left(I_{\mathrm{CN}, 7}\right)$ & $7.29 \pm 0.11$ & $7.43 \pm 0.11$ & $8.61 \pm 0.12$ & $13.04 \pm 0.11$ & $17.48 \pm 0.12$ & $19.03 \pm 0.14$ \\
\hline$a_{8}\left(I_{\mathrm{CN}, 8}\right)$ & $-3.48 \pm 0.14$ & $-4.47 \pm 0.13$ & $-4.84 \pm 0.14$ & $0.50 \pm 0.14$ & $8.35 \pm 0.14$ & $12.49 \pm 0.17$ \\
\hline$a_{9}\left(I_{\mathrm{CN}, 9}\right)$ & $9.12 \pm 0.16$ & $9.37 \pm 0.15$ & $11.41 \pm 0.17$ & $11.72 \pm 0.16$ & $21.73 \pm 0.17$ & $31.74 \pm 0.20$ \\
\hline$a_{10}\left(I_{\mathrm{CN}, 10}\right)$ & $14.24 \pm 0.15$ & $15.75 \pm 0.14$ & $17.56 \pm 0.16$ & $16.60 \pm 0.15$ & $12.40 \pm 0.16$ & $13.85 \pm 0.19$ \\
\hline$a_{11} \operatorname{sqrt}($ Lon $)$ & $0.87 \pm 0.17$ & $-6.90 \pm 0.16$ & $-13.08 \pm 0.18$ & $-6.29 \pm 0.17$ & $-5.49 \pm 0.18$ & $-9.14 \pm 0.21$ \\
\hline$a_{12} \operatorname{sqrt}(\mathrm{Lat})$ & $-23.14 \pm 0.32$ & $-17.79 \pm 0.30$ & $-21.13 \pm 0.34$ & $-20.94 \pm 0.32$ & $-18.99 \pm 0.33$ & $-24.79 \pm 0.40$ \\
\hline$a_{13} \operatorname{sqrt}(H)$ & $-0.24 \pm 0.00$ & $-0.28 \pm 0.00$ & $-0.43 \pm 0.00$ & $-0.51 \pm 0.00$ & $-0.47 \pm 0.00$ & $-0.42 \pm 0.01$ \\
\hline$\lambda_{1}$ & 0.525 & 0.785 & 1.156 & 1.375 & 1.365 & 1.555 \\
\hline$K_{1}$ & 8.278 & 2.671 & 0.463 & 0.137 & 0.127 & 0.039 \\
\hline$R^{2}($ ANOVA $p)$ & $0.88(p<0.001)$ & $0.89(p<0.001)$ & $0.90(p<0.001)$ & $0.93(p<0.001)$ & $0.94(p<0.001)$ & $0.93(p<0.001)$ \\
\hline Durbin-Watson $(p)$ & $1.99(p=0.24)$ & $2.00(p=0.50)$ & $2.00(p=0.43)$ & $2.00(p=0.47)$ & $1.99(p=0.28)$ & $2.00(p=0.43)$ \\
\hline Month & Jul & Aug & Sep & Oct & Nov & Dec \\
\hline Regression coefficient & Mean \pm S.E. & Mean \pm S.E. & Mean \pm S.E. & Mean \pm S.E. & Mean \pm S.E. & Mean \pm S.E. \\
\hline$a_{0}$ (intercept) & $431.49 \pm 3.74$ & $381.54 \pm 3.25$ & $258.85 \pm 2.06$ & $210.73 \pm 2.29$ & $192.59 \pm 2.08$ & $163.20 \pm 2.31$ \\
\hline$a_{1}\left(I_{\mathrm{CN}, 1}\right)$ & $-9.68 \pm 0.12$ & $-9.61 \pm 0.10$ & $-7.70 \pm 0.07$ & $-9.92 \pm 0.07$ & $-7.88 \pm 0.07$ & $-8.42 \pm 0.07$ \\
\hline$a_{2}\left(I_{\mathrm{CN}, 2}\right)$ & $-24.04 \pm 0.18$ & $-22.25 \pm 0.15$ & $-16.37 \pm 0.10$ & $-16.90 \pm 0.11$ & $-13.49 \pm 0.10$ & $-13.02 \pm 0.11$ \\
\hline$a_{3}\left(I_{\mathrm{CN}, 3}\right)$ & $-40.47 \pm 0.27$ & $-36.64 \pm 0.23$ & $-26.21 \pm 0.15$ & $-24.19 \pm 0.16$ & $-18.10 \pm 0.15$ & $-16.08 \pm 0.17$ \\
\hline$a_{4}\left(I_{\mathrm{CN}, 4}\right)$ & $-58.04 \pm 0.45$ & $-52.24 \pm 0.39$ & $-35.99 \pm 0.25$ & $-29.00 \pm 0.27$ & $-19.62 \pm 0.25$ & $-17.01 \pm 0.28$ \\
\hline$a_{5}\left(I_{\mathrm{CN}, 5}\right)$ & $3.35 \pm 0.12$ & $1.79 \pm 0.10$ & $0.03 \pm 0.06$ & $-1.65 \pm 0.07$ & $-1.59 \pm 0.06$ & $-2.23 \pm 0.07$ \\
\hline$a_{6}\left(I_{\mathrm{CN}, 6}\right)$ & $13.52 \pm 0.14$ & $11.33 \pm 0.12$ & $8.33 \pm 0.08$ & $6.64 \pm 0.09$ & $5.79 \pm 0.08$ & $5.03 \pm 0.09$ \\
\hline$a_{7}\left(I_{\mathrm{CN}, 7}\right)$ & $25.19 \pm 0.19$ & $22.14 \pm 0.16$ & $15.58 \pm 0.10$ & $12.26 \pm 0.11$ & $9.10 \pm 0.10$ & $7.56 \pm 0.12$ \\
\hline$a_{8}\left(I_{\mathrm{CN}, 8}\right)$ & $20.64 \pm 0.23$ & $17.23 \pm 0.20$ & $7.98 \pm 0.13$ & $-1.21 \pm 0.14$ & $-3.54 \pm 0.13$ & $-4.17 \pm 0.14$ \\
\hline$a_{9}\left(I_{\mathrm{CN}, 9}\right)$ & $42.02 \pm 0.27$ & $37.20 \pm 0.23$ & $25.93 \pm 0.15$ & $18.76 \pm 0.17$ & $11.75 \pm 0.15$ & $9.71 \pm 0.17$ \\
\hline$a_{10}\left(I_{\mathrm{CN}, 10}\right)$ & $12.08 \pm 0.26$ & $13.06 \pm 0.22$ & $12.23 \pm 0.14$ & $18.90 \pm 0.16$ & $16.19 \pm 0.14$ & $16.63 \pm 0.16$ \\
\hline$a_{11} \operatorname{sqrt}($ Lon $)$ & $-8.93 \pm 0.28$ & $5.37 \pm 0.25$ & $12.92 \pm 0.16$ & $-2.16 \pm 0.17$ & $3.21 \pm 0.16$ & $3.45 \pm 0.17$ \\
\hline$a_{12}$ sqrt(Lat) & $-18.17 \pm 0.53$ & $-22.56 \pm 0.46$ & $-29.67 \pm 0.29$ & $-20.50 \pm 0.33$ & $-24.50 \pm 0.30$ & $-21.50 \pm 0.33$ \\
\hline$a_{13} \operatorname{sqrt}(H)$ & $-0.41 \pm 0.01$ & $-0.45 \pm 0.01$ & $-0.44 \pm 0.00$ & $-0.41 \pm 0.00$ & $-0.32 \pm 0.00$ & $-0.29 \pm 0.00$ \\
\hline$\lambda_{1}$ & 0.663 & 0.620 & 0.895 & 1.211 & 0.783 & 0.656 \\
\hline$K_{1}$ & 8.675 & 11.186 & 1.828 & 0.337 & 2.767 & 4.578 \\
\hline$R^{2}($ ANOVA $p)$ & $0.91(p<0.001)$ & $0.93(p<0.001)$ & $0.96(p<0.001)$ & $0.93(p<0.001)$ & $0.92(p<0.001)$ & $0.89(p<0.001)$ \\
\hline Durbin-Watson $(p)$ & $2.00(p=0.41)$ & $2.00(p=0.39)$ & $2.00(p=0.38)$ & $2.01(p=0.15)$ & $1.99(p=0.29)$ & $1.99(p=0.25)$ \\
\hline
\end{tabular}

is described by the sum term inside (2), is given in Figure 6. According to Figure 6, clusters 1, 2, 3, and 4 present a negative effect while clusters $6,7,9,10$, and 11 present a positive effect to all months. The effect of clusters 5 and 8 presents small positive values during the warm season and small negative values during the cold season. The contribution of each cluster (Figure 6) defines the relative behaviour of each cluster during each month using, as a reference, the mean monthly conditions of $\mathrm{ET}_{o}$ in the Greek territory.

\section{Conclusions}

The derived high resolution dataset of mean monthly $\mathrm{ET}_{o}$ and the statistical analysis captured the seasonal and spatial variation of $\mathrm{ET}_{o}$ in Greece while the regional spatiotemporal trends were revealed and assigned to spatial clusters. More specifically, cross-correlation and principal component analysis quantified the temporal pattern of $\mathrm{ET}_{o}$ and revealed season, latitude, longitude, and elevation dependencies, while 

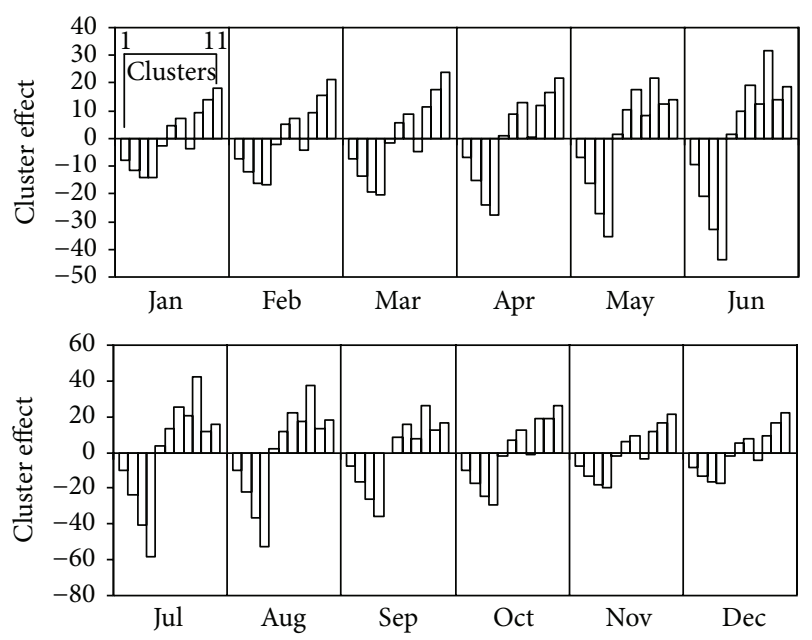

FIGURE 6: The contribution/effect of each cluster in the spatiotemporal variation of $\mathrm{ET}_{o}$ in the Greek territory as it is described by the sum term inside (2).

$K$-means cluster analysis segmented the terrain to regions with distinct temporal variability of $\mathrm{ET}_{o}$. The derived spatiotemporal patterns are in accordance with previous research efforts.

The parameterization of each cluster (revealing a unique temporal signature of monthly $\mathrm{ET}_{o}$ ) together with topography (elevation) and spatial arrangement (latitude and longitude) described satisfactorily the mean monthly $\mathrm{ET}_{o}$ through generalized linear models verifying the robustness of the cluster analysis, providing also a tool for $\mathrm{ET}_{o}$ estimations for agricultural purposes. The feasible development of high resolution grids of monthly $\mathrm{ET}_{o}$ based on available meteorological data produced by climatic models and the terrain segmentation approach can be used as tools to design decision support and management schemes of water recourses.

The procedures described in this study can be used as a general framework for the spatial and seasonal variation not only for $\mathrm{ET}_{o}$ but also for other climatic parameters while it can support future research efforts such as

(a) assessing any climate changes by integrating monthly $\mathrm{ET}_{o}$ data sets or other climatic variables of the forecoming years; the new data sets can be used to recompute the temporal pattern of the climatic variable within each cluster in an attempt to evaluate any trends in the centroid change between two periods;

(b) using the proposed framework at watershed scale in order to facilitate the surface integration of climatic variables obtained by meteorological stations based on clusters produced by long-term data such as the ones of this study.

\section{Conflict of Interests}

The authors declare that there is no conflict of interests regarding the publication of this paper.

\section{References}

[1] R. G. Allen, L. S. Pereira, D. Raes, and M. Smith, "Crop evapotranspiration: guidelines for computing crop water requirements," Irrigation and Drainage Paper 56, Food and Agriculture Organization of the United Nations, Rome, Italy, 1998.

[2] R. G. Allen, I. A. Walter, R. Elliott, T. Howell, D. Itenfisu, and M. Jensen, "The ASCE standardized reference evapotranspiration equation.Final Report (ASCE-EWRI)," in Task Committee on Standardization of Reference Evapotranspiration of the Environmental and Water Resources Institute, R. G. Allen, I. A. Walter, R. Elliott, T. Howell, D. Itenfisu, and M. Jensen, Eds., Environmental and Water Resources Institute, 2005.

[3] R. Kumar, M. K. Jat, and V. Shankar, "Methods to estimate irrigated reference crop evapotranspiration-a review," Water Science and Technology, vol. 66, no. 3, pp. 525-535, 2012.

[4] N. R. Dalezios, Z. G. Papazafiriou, D. M. Papamichail, and T. S. Karacostas, "Drought assessment for the potential of precipitation enhancement in northern Greece," Theoretical and Applied Climatology, vol. 44, no. 2, pp. 75-88, 1991.

[5] N. R. Dalezios, A. Loukas, and D. Bampzelis, "Spatial variability of reference evapotranspiration in Greece," Physics and Chemistry of the Earth, vol. 27, no. 23-24, pp. 1031-1038, 2002.

[6] J. Alexiou and D. Papamichail, "Application of geostatistics to spatial variability of reference evapotranspiration," in Proceedings of the 2nd Hellenic Conference on Water Management, vol. A, pp. 223-245, Geotechnical Chamber of Greece, Larisa, Greece, April 1996 (Greek).

[7] D. M. Papamichail and G. A. Terzidis, "Assessment of the meteorological parameters effects on the daily Penman reference evapotranspiration," Acta Horticulturae, vol. 49, pp. 281288, 1996, Proceedings of the 2nd International Symposium on Irrigation of Horticultural Crops, Chania, Greece.

[8] D. Papamichail D and J. Alexiou, "Application of the theory of regionalized variables for estimating reference evapotranspiration in Greece," in Proceedings of the International Conference Protection and Restoration of the Environment IV, vol. I, pp. 222229, Sani Halkidiki, Greece, July 1998.

[9] S. Kotsopoulos and C. Babajimopoulos, "Analytical estimation of modified penman equation parameters," Journal of Irrigation and Drainage Engineering, vol. 123, no. 4, pp. 253-256, 1997.

[10] S. Alexandris and P. Kerkides, "New empirical formula for hourly estimations of reference evapotranspiration," Agricultural Water Management, vol. 60, no. 3, pp. 157-180, 2003.

[11] M. G. Mardikis, D. P. Kalivas, and V. J. Kollias, "Comparison of interpolation methods for the prediction of reference evapotranspiration-an application in Greece," Water Resources Management, vol. 19, no. 3, pp. 251-278, 2005.

[12] J. D. Valiantzas, "Simplified versions for the Penman evaporation equation using routine weather data," Journal of Hydrology, vol. 331, no. 3-4, pp. 690-702, 2006.

[13] K. Kostinakis, F. Xystrakis, K. Theodoropoulos, D. Stathis, E. Eleftheriadou, and A. Matzarakis, "Estimation of reference potential evapotranspiration with focus on vegetation sciencethe EmPEst Software," Journal of Irrigation and Drainage Engineering, vol. 137, no. 9, pp. 616-619, 2011.

[14] M. J. Diamantopoulou, P. E. Georgiou, and D. M. Papamichail, "Performance evaluation of artificial neural networks in estimating reference evapotranspiration with minimal meteorological data," Global Nest Journal, vol. 13, no. 1, pp. 18-27, 2011.

[15] F. Xystrakis and A. Matzarakis, "Evaluation of 13 empirical reference potential evapotranspiration equations on the island 
of crete in southern Greece," Journal of Irrigation and Drainage Engineering, vol. 137, no. 4, pp. 211-222, 2011.

[16] V. T. Ambas and E. Baltas, "Sensitivity analysis of different evapotranspiration methods using a new sensitivity coefficient," Global Nest Journal, vol. 14, no. 3, pp. 335-343, 2012.

[17] S. Paparrizos, F. Maris, and A. Matzarakis, "Estimation and comparison of potential evapotranspiration based on daily and monthly data from sperchios valley in central Greece," Global Nest Journal, vol. 16, no. 1, pp. 204-217, 2014.

[18] D. A. Samaras, A. Reif, and K. Theodoropoulos, "Evaluation of radiation-based reference evapotranspiration models under different Mediterranean climates in central Greece," Water Resources Management, vol. 28, no. 1, pp. 207-225, 2014.

[19] R. Tateishi and C. H. Ahn, "Mapping evapotranspiration and water balance for global land surfaces," ISPRS Journal of Photogrammetry and Remote Sensing, vol. 51, no. 4, pp. 209-215, 1996.

[20] P. Droogers and R. G. Allen, "Estimating reference evapotranspiration under inaccurate data conditions," Irrigation and Drainage Systems, vol. 16, no. 1, pp. 33-45, 2002.

[21] M. Weiß and L. Menzel, "A global comparison of four potential evapotranspiration equations and their relevance to stream flow modelling in semi-arid environments," Advances in Geosciences, vol. 18, pp. 15-23, 2008.

[22] R. J. Zomer, A. Trabucco, D. A. Bossio, and L. V. Verchot, "Climate change mitigation: a spatial analysis of global land suitability for clean development mechanism afforestation and reforestation," Agriculture, Ecosystems and Environment, vol. 126, no. 1-2, pp. 67-80, 2008.

[23] G. H. Hargreaves and Z. A. Samani, "Reference crop evapotranspiration from temperature," Applied Engineering in Agriculture, vol. 1, no. 2, pp. 96-99, 1985.

[24] H. Wackernagel, Multivariate Geostatistics: An Introduction with Applications, Springer, Berlin, Germany, 2003.

[25] C. Baeza, N. Lantada, and J. Moya, "Validation and evaluation of two multivariate statistical models for predictive shallow landslide susceptibility mapping of the Eastern Pyrenees (Spain)," Environmental Earth Sciences, vol. 61, no. 3, pp. 507-523, 2010.

[26] H. Wang and S. Lu, "Spatial distribution, source identification and affecting factors of heavy metals contamination in urbansuburban soils of Lishui city, China," Environmental Earth Sciences, vol. 64, no. 7, pp. 1921-1929, 2011.

[27] D. Liu, S. Hao, X. Liu, B. Li, S. He, and D. N. Warrington, "Effects of land use classification on landscape metrics based on remote sensing and GIS," Environmental Earth Sciences, vol. 68, no. 8, pp. 2229-2237, 2013.

[28] V. G. Aschonitis, M. Mastrocicco, N. Colombani et al., "Assessment of the intrinsic vulnerability of agricultural land to water and nitrogen losses via deterministic approach and regression analysis," Water, Air, and Soil Pollution, vol. 223, no. 4, pp. 16051614, 2012.

[29] V. G. Aschonitis, E. Salemi, N. Colombani, G. Castaldelli, and M. Mastrocicco, "Formulation of indices to describe intrinsic nitrogen transformation rates for the implementation of best management practices in agricultural lands," Water, Air, and Soil Pollution, vol. 224, article 1489, 2013.

[30] M. Marchetti, L. Chapman, A. Khalifa, and M. Buès, "New role of thermal mapping in winter maintenance with principal components analysis," Advances in Meteorology, vol. 2014, Article ID 254795, 11 pages, 2014.
[31] E. E. Maeda and P. Hurskainen, "Spatiotemporal characterization of land surface temperature in Mount Kilimanjaro using satellite data," Theoretical and Applied Climatology, vol. 118, no. 3, pp. 497-509, 2014.

[32] G. C. Miliaresis, "Regional thermal and terrain modelling of the Afar Depression from MODIS multi-temporal monthly night LST data," International Journal of Remote Sensing, vol. 30, no. 9, pp. 2429-2446, 2009.

[33] G. Miliaresis and P. Partsinevelos, “Terrain segmentation of Egypt from multi-temporal night lst imagery and elevation data," Remote Sensing, vol. 2, no. 9, pp. 2083-2096, 2010.

[34] G. C. Miliaresis and A. Tsatsaris, "Thermal terrain modeling of spatial objects, a tool for environmental and climatic change assessment," Environmental Monitoring and Assessment, vol. 164, no. 1-4, pp. 561-572, 2010.

[35] G. C. Miliaresis, "Thermal anomaly mapping from night MODIS imagery of USA, a tool for environmental assessment," Environmental Monitoring and Assessment, vol. 185, no. 2, pp. 1601-1612, 2013.

[36] G. C. Miliaresis, "Spatiotemporal patterns of land surface temperature of Antarctica from MODIS monthly LST (MYD11C3) data," Journal of Spatial Science, vol. 59, no. 1, pp. 157-166, 2014.

[37] C. Li-Juan, C. De-Liang, W. Hui-Jun, and Y. Jing-Hui, "Regionalization of precipitation regimes in China," Atmospheric and Oceanic Science Letters, vol. 2, no. 5, pp. 301-307, 2009.

[38] G. Buttafuoco, T. Caloiero, and R. Coscarelli, "Spatial and temporal patterns of the mean annual precipitation at decadal time scale in southern Italy (Calabria region)," Theoretical and Applied Climatology, vol. 105, no. 3, pp. 431-444, 2011.

[39] K. Demertzi, D. Papamichail, V. Aschonitis, and G. Miliaresis, "Spatial and seasonal patterns of precipitation in Greece: the terrain segmentation approach," Global Nest Journal, vol. 16, no. 5, pp. 988-997, 2014.

[40] R. J. Hijmans, S. E. Cameron, J. L. Parra, P. G. Jones, and A. Jarvis, "Very high resolution interpolated climate surfaces for global land areas," International Journal of Climatology, vol. 25, no. 15, pp. 1965-1978, 2005.

[41] J. Sheffield, G. Goteti, and E. F. Wood, "Development of a 50year high-resolution global dataset of meteorological forcings for land surface modeling," Journal of Climate, vol. 19, no. 13, pp. 3088-3111, 2006.

[42] J. P. Peixoto and A. H. Oort, "The climatology of relative humidity in the atmosphere," Journal of Climate, vol. 9, no. 12, pp. 3443-3463, 1996.

[43] K. Demertzi, V. Aschonitis, and D. Papamichail, "Analysis of Priestley-Taylor method for the assessment of reference evapotranspiration in Greece," Hydrotechnica, vol. 22, pp. 1-14, 2013 (Greek).

[44] H. Liu, X. Zhang, L. Zhang, and X. Wang, "Changing trends in meteorological elements and reference evapotranspiration in a mega city: a case study in Shenzhen city, China," Advances in Meteorology, vol. 2015, Article ID 324502, 11 pages, 2015.

[45] D. R. Helsel and R. M. Hirsch, Statistical Methods in Water Resources Techniques of Water Resources Investigations, book 4, chapter A3, US Geological Survey, 2002.

[46] D. M. Wolock, T. C. Winter, and G. McMahon, "Delineation and evaluation of hydrologic-landscape regions in the United States using geographic information system tools and multivariate statistical analyses," Environmental Management, vol. 34, pp. S71-S88, 2004. 
[47] K. Kevin and T. Neil, Univariate and Multivariate General Linear Models: Theory and Applications with SAS, CRC Press, 2nd edition, 2006.

[48] R. A. Johnson and D. W. Wichern, Applied Multivariate Statistical Analysis, Pearson Prentice Hall, Upper Saddle River, NJ, USA, 6th edition, 2007.

[49] L. Maaten and G. Hinton, "Visualizing data using t-SNE," Journal of Machine Learning Research, vol. 9, pp. 2579-2605, 2008.

[50] A.-I. Petrişor, I. Ianoş, D. Iurea, and M.-N. Văidianu, "Applications of principal component analysis integrated with GIS," Procedia Environmental Sciences, vol. 14, pp. 247-256, 2012.

[51] P. M. Mather, Computer Processing of Remotely-Sensed Images, John Wiley \& Sons, New York, NY, USA, 3rd edition, 2004.

[52] P. A. Siljestrom, A. Moreno, G. Vikgren, and L. M. Caceres, "The application of selective principal components analysis to a thematic mapper image for the recognition of geomorphologic features configuration," International Journal of Remote Sensing, vol. 18, pp. 3843-3852, 1997.

[53] J. R. Eastman and M. Fulk, "Long sequence time series evaluation using standardized principal components," Photogrammetric Engineering and Remote Sensing, vol. 59, no. 8, pp. 1307-1312, 1993.

[54] G. E. Box and D. R. Cox, "An analysis of transformations," Journal of the Royal Statistical Society Series B: Methodological, vol. 26, pp. 211-252, 1964.

[55] J. Durbin and G. S. Watson, "Testing for serial correlation in least squares regression, I," Biometrika, vol. 37, pp. 409-428, 1950.

[56] J. Durbin and G. S. Watson, "Testing for serial correlation in least squares regression II," Biometrika, vol. 38, pp. 159-178, 1951.

[57] P. Kerkides, H. Michalopoulou, G. Papaioannou, and R. Pollatou, "Water balance estimates over Greece," Agricultural Water Management, vol. 32, no. 1, pp. 85-104, 1996.

[58] G. Papaioannou, G. Kitsara, N. Melanitis, A. Mitropoulou, P. Kerkides, and P. Giannoulopoulos, "Temporal analysis of hydrometeorological characteristics in Crete," in Proceedings of the International Conferences in Water Resources Management: New Approaches and Technologies, European Water Resources Association, Chania, Greece, 2007.

[59] P. E. Georgiou, D. M. Papamichail, and Z. Papazafiriou, "Comparative analysis of Penman and Penman-Monteith methods by using reference evapotranspiration estimates over Greece," in Proceedings of the 5th Hellenic Conference on Meteorology, Climatology and Atmospheric Physics, pp. 395-402, Thessaloniki, Greece, 2000, in Greek. 

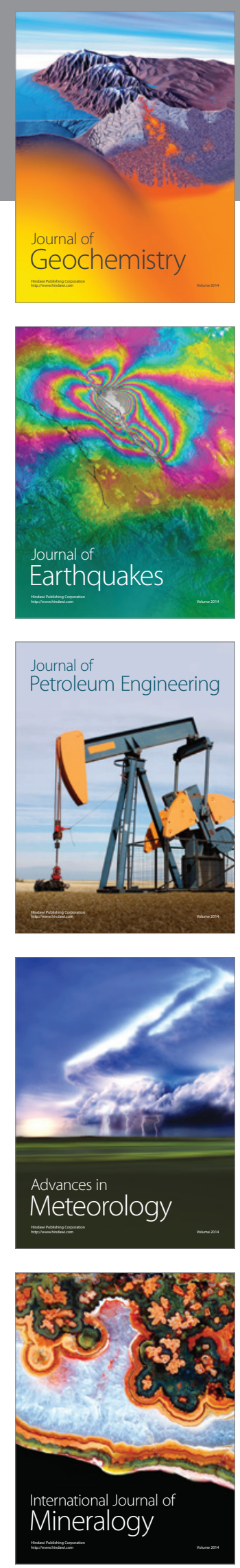
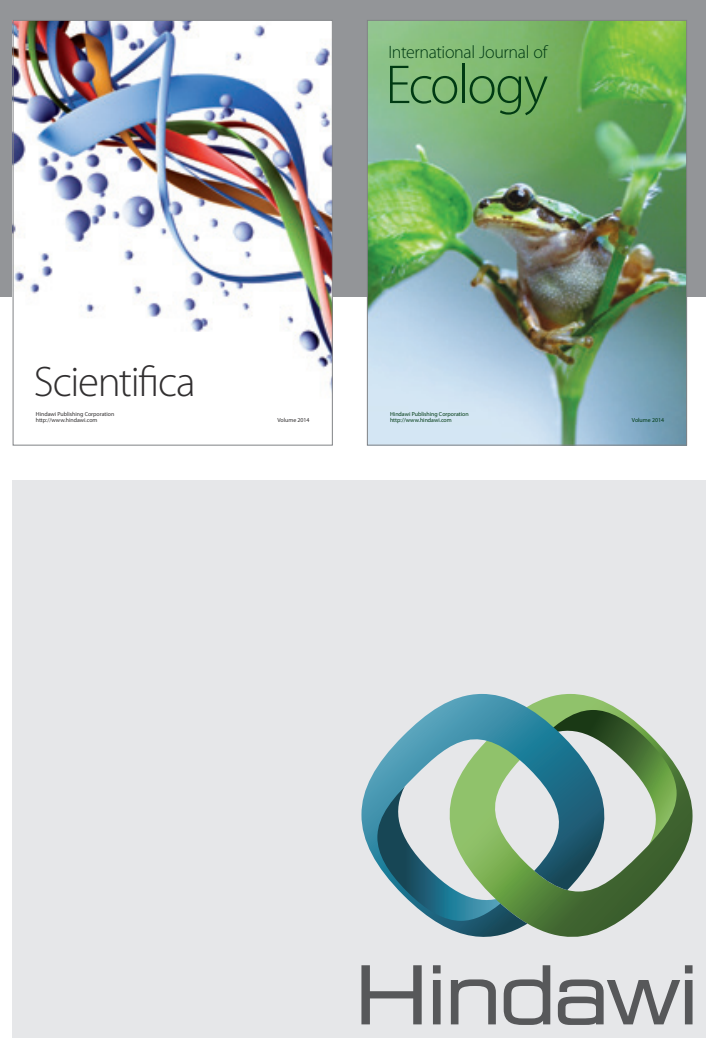

Submit your manuscripts at

http://www.hindawi.com
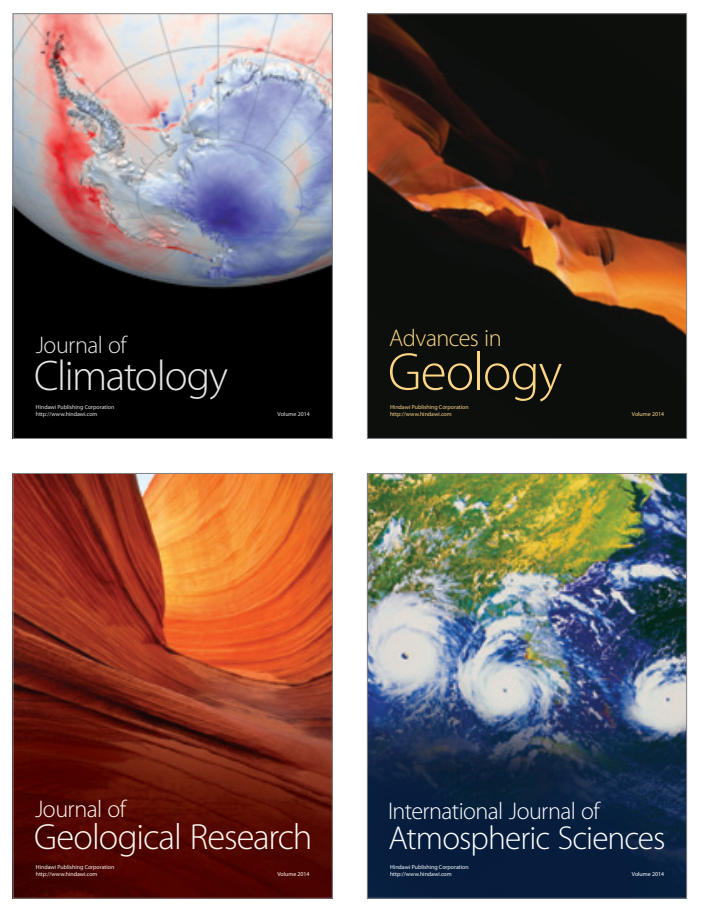

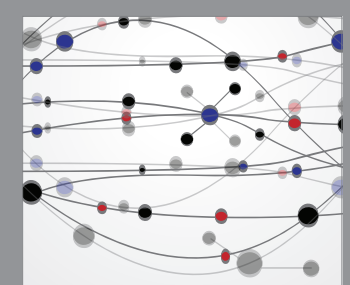

The Scientific

\section{World Journal}
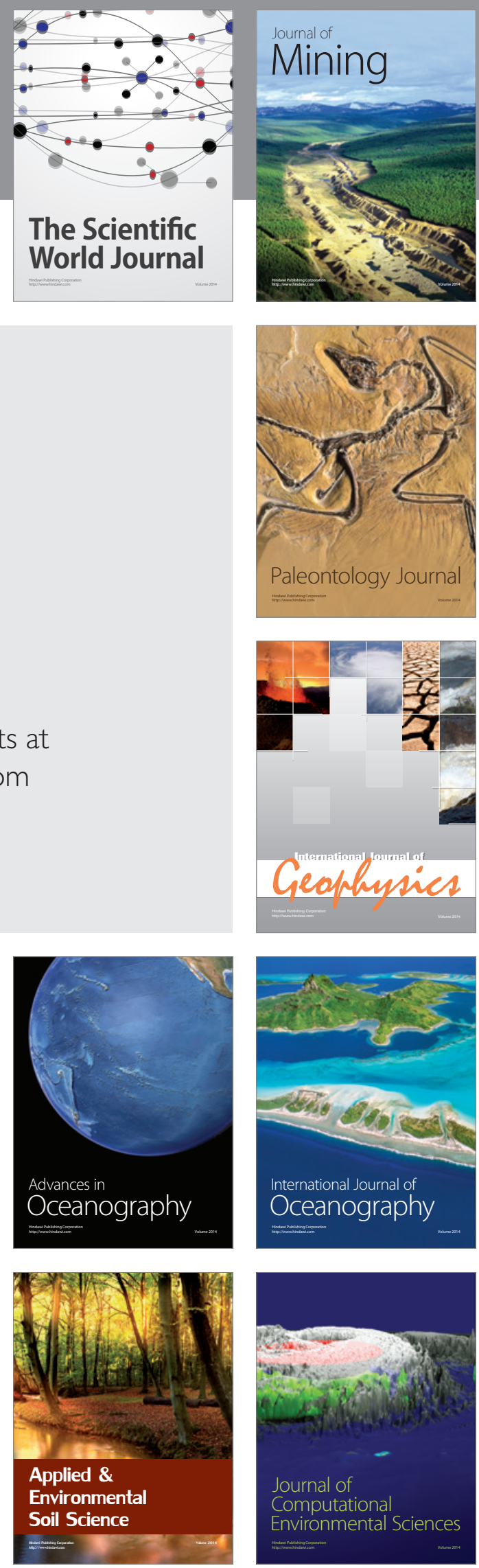